\section{Almost all about symmetry}

\author{
Simon Altmann
}

Symmetries of Nature: A Handbook for Philosophy of Nature and Science. By Klaus Mainzer. Walter de Gruyter: 1996. Pp. 681. DM338.

ANAXIMANDER, the author of probably the first philosophy book, was the first to use a symmetry argument, according to Aristotle's De Caelo. This argument deduced the equilibrium of the Earth from the equi-distribution of the celestial bodies. It was the fountain-head of the great intellectual line that sprung from it, via Leibniz's "principle of sufficient reason", to Pierre Curie, who gave the first clear and complete enunciation of the "principle of symmetry".

All this and much more is in Klaus Mainzer's book. But readers cannot expect his overview to hit them in the eye. Mainzer's work has to be used more or less on the same principles as those articulated by Jorge Luis Borges' cartographers who produced a map of their country at a scale of 1 to 1 . Everything is there, nothing is missed, but nothing is added either. So readers have to find their own route and even draw their own conclusions.

Take, for example, the third prong of Curie's principle, which states that the effects can be more symmetrical than the causes. (I am translating from the French, as the English version is seriously wrong, whether by mistake in the original or mistranslation from the German.) As Bertrand Russell said, the words 'cause' and 'effect' are not much used in science, but they happen to be part of the traditional vocabulary of symmetry theory. Scientists differ from many philosophers in that they never use the word 'cause' unless its absence implies the absence of the effect too (think about a force and its attendant acceleration). This is a condition that Curie's 'cause' does not satisfy, as follows from his rule as stated above.

One might have expected attention to this problem in the text, as this is claimed to be a book on the philosophy of science. But not a word on it will one find. Neither is there anything about the fact that the first two prongs of Curie's law are contrapositive and so logically equivalent. There is no discussion of the physical reasons that allow symmetry to be created where it did not exist, although this is a crucially important fact.

On the other hand, many topics are treated well. I particularly enjoyed the way in which Mainzer moves from the Platonic solids to their counterparts in four- and higher-dimensional spaces, and his approach to colour symmetry by relating it to musical symmetries. And there is a great deal on Lie and Galois groups, and on symmetries in electromagnetism, relativity, classical and quantum mechanics, and elementary particles. I am not sure, however, why a Schrödinger cat has to be asphyxiated in a book on symmetry. But surely, if such activities are necessary, to dismiss the hapless animal as of "historical" value flies in the face of the evidence of the important, copious and entirely current literature on the subject.

As for relativity, I am not happy about the assertion that the MichelsonMorley experiment "confirms only the isotropy of the propagation of light". At least in the literature in English, isotropy is understood in this context to include the propagation of light along the same line in two opposite directions. The MichelsonMorley experiment would have saved a lot of theorists a great deal of sweat if it had been able to prove that these velocities are identical.

One serious problem with this book is that the German original is ten years old, and it shows. Mention is made of one of Jean Piaget's books on children's acquisition of the notions of movement and speed, without any reference to experiments by Jacques Mehler in Paris (already well known in the 1970s) that throw doubt on some of Piaget's results. Admittedly, Bas van Fraassen's admirable book Laws and Symmetries appeared too late for the German edition, but it is a great pity that the opportunity was not taken to use it when preparing the translation. (It might be unrealistic to expect such refinements in this edition, however, when no one seems to have thought it necessary to make sure that English books are cited in the original rather than in German translation.)

One of the most important philosophical problems raised by the principle of symmetry is that, badly used, it invites the delusion that symmetry allows for some sort of a priori knowledge. It is not sufficient in a book like this to say that this principle can be of "great heuristic use" subject to whatever caveats, if these caveats are not thoroughly spelt out. Poor Ørsted wasted eight years of work because of the wrong application of a symmetry principle, and he had a first-class mind.

On the now established tradition in symmetry of the cultural grand tour, art is also included here but the choice of periods is idiosyncratic. Early art and even postmodern architecture are in, but the important problem of right and left in the iconography of the Annunciation is not mentioned. And perhaps something about symmetry-breaking, as for instance by Antonio da Sangallo in the fenestration of the Palazzo Farnese in Rome, or by Fracesco Borromini's glide plane in the balustrades of San Carlino, also in Rome, would have been appropriate. As for the postmodern period, surely the supreme example of symmetry-breaking is Hans Hollein's Haas Haus opposite St Stephen's Cathedral in Vienna.

But the most dramatic use of symmetry in architecture is the iconic one, which has given us the great divide between the style of Mies van der Rohe and the postmodern approach of his most famous pupil, Philip Johnson. This was forcefully displayed in 1979 by Johnson's broken pediment on the then AT\&T building in Manhattan, which for many of us was the harbinger of the new order. Or is it disorder? Or is it a Kuhnian change of paradigm? It is a shame that the author does not discuss this, the most fascinating problem of present-day architecture.

Simon Altmann is at Brasenose College, Oxford OX1 4A, UK.

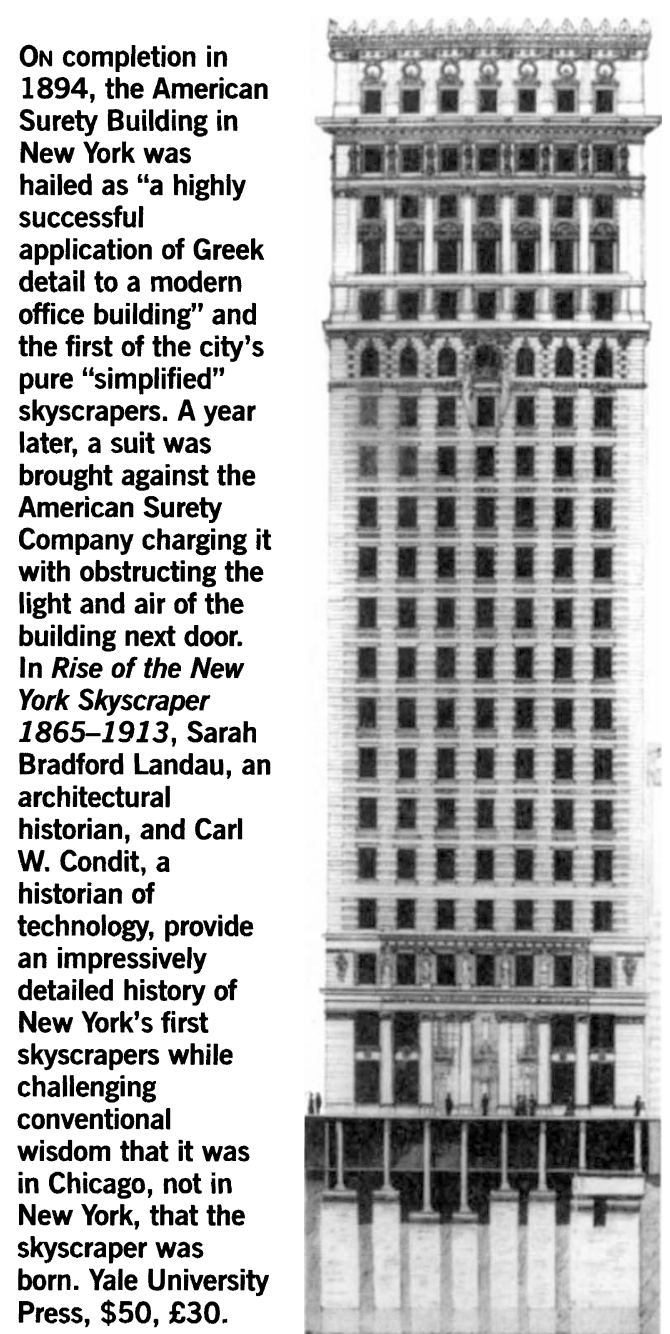

ON completion in

Surety Building in

New York was

hailed as "a highly

detail to a modern

office building" and

the first of the city's

pure "simplified"

pkyscrapers. A year

brought against the

American Surety

Company charging it

light and air of the

building next door.

In Rise of the New

ork Skyscrape

architectural

historian, and Car

technology, provide

an impressively

skyscrapers while

challenging

Press, $\$ 50, £ 30$. 